\title{
Report on US nuclear repository 'needs effective peer review'
}

Washington. An independent panel of scientists has harshly criticized a key part of the process which the US Department of Energy (DoE) is using to decide about the use of Yucca Mountain in Nevada as a repository for the long-term storage of nuclear waste.

The department is preparing a series of six Technical Basis Reports (TBRs). These are supposed to present the science that will underpin its final decision, due in 1998, on whether Yucca Mountain is fit for the purpose.

But in a stinging rebuttal of the first such report - on surface characteristics, hydrology and erosion - a panel of the National Research Council (NRC) says that the DoE failed to include the right data, and did not present it in the right way.

"The DoE report is deficient," says Ernest Smerdon, dean of engineering and mines at the University of Arizona, Tucson, and chair of the NRC panel. "It is not written clearly for a broad audience and does not include adequate supporting data for some of its analyses."

Jean Bahr of the geology and geophysics department at the University of Wisconsin at Madison, vice-chair of the panel, says that the criticism is of the report, not the underlying science.

"They don't have the support here that they'll need to convince people" that their decision on Yucca Mountain is the right one, she says. The NRC found that "many of the problems noted in this report could have been discovered and corrected had an effective peer review mechanism been in place".

The DoE reports were supposed to provide intellectual ballast for a decision on Yucca Mountain that is bound to be extremely controversial. The NRC's criticism may improve the prospects of their doing so in the long term - but may also fuel fears that DoE is mismanaging the entire project.

The report was jumped on by officials in the state of Nevada, which opposes the repository. Carl Johnson of the Nevada Nuclear Waste Project Office says that the findings bear out the state's view that the DoE has performed "a very narrow analysis, only using the DoE's own data".

The latest report only adds to the Yucca project's woes. The Department of Energy is now re-planning the project after the imposition of sharp cuts in its budget appropriation. Eight hundred contractor staff have been fired, the remaining five TBRs may be rolled into one, and the 1998 decision date may be moved back.

Colin Macilwain

\section{Planetary defence mission to yield pay-off for research}

Washington. The US Air Force plans to launch a spacecraft in 1998 to approach several near-Earth asteroids and send microsatellites crashing into their surfaces to study the resulting impacts. But the National Aeronautics and Space Administration (NASA) may have mixed feelings about the military encroaching on its turf.

The mission, planned as a follow-on to the Clementine project that mapped the Moon last year but failed before reaching an asteroid (see Nature 367, 207; 1994), will test advanced satellite technology and provide data for a new Air Force programme designed for defence against the threat of Earth-crossing asteroids.

The 1996 defence appropriations bill approved by President Bill Clinton last week includes $\$ 20$ million for the Clementine 2 project. Its total cost is expected to be below $\$ 80$ million, according to Stewart, the head of the project, who was deputy manager for Clementine 1.

Nozette and the team from the Naval Research Laboratory (NRL) that built and flew the original Clementine have been searching for another assignment ever since a software glitch abruptly ended their first mission in May 1994. Proposals to NASA to fly a replacement for the lost Mars Observer and to send a spacecraft to the Moon as part of the space agency's Discovery series of low-budget planetary missions were both turned down.

Now the Air Force has agreed to fund Clementine 2 as part of a new "planetary defence" programme which, according to Colonel Simon Worden of the Air Force Space Command, has become "part of our mission statement"

The plan will be developed in detail over the next three months. It calls for a main spacecraft to carry several $10-\mathrm{kg}$ microsatellites that will be sent hurtling into their targets at speeds of 5 to $10 \mathrm{~km}$ per second. Instruments on the main spacecraft will then observe the impacts and resulting craters.

The spacecraft could meet up with between two and six asteroids over the course of a two-year mission, says Nozette. Apart from the Clementine team at NRL, the project involves participation from the Air Force Phillips Laboratory and Lawrence Livermore National Laboratory.

Clementine 2 is seen as the first in a series of Air Force spacecraft that would eventually sample 20 to 30 Earth-crossing asteroids. The goal of this first mission, says Nozette, is to show that asteroid encounters can be done cheaply, using technologies even more advanced and miniaturized that those that flew on Clementine 1.

NASA's participation in the project is still to be decided. In its 1996 authorization bill for the space agency, the House of Representatives Science Committee instructed it to use \$5 million of its \$30 million 1996 budget for the New Millennium technology development programme to cooperate on the Clementine 2 mission. But that bill is unlikely to pass this year, making the instruction non-binding.

Project managers for New Millennium say they still intend to cooperate with the Clementine team, perhaps sharing some technology development. But the NASA team has its own plans for an asteroid/comet fly-by mission in 1998, which would also demonstrate a suite of advanced technologies, including solar electric propulsion.

The two missions will in fact be competing fiercely to see which of them can build the cleverest spacecraft at the lowest cost. Competition is good, say science committee members, as long as the two sides do not duplicate each other's efforts.

In both cases, scientists will only be going along for the ride. Ninety per cent of the objectives for the first New Millennium mission are technology-related, even though the programme is designed to produce new sensors and spacecraft capabilities which could then be used on future science missions. And, as with Clementine 1 , the Clementine 2 mission will be primarily a hardware demonstration.

This trend towards relegating science to the back seat on demonstration flights worries some space scientists. But Eugene Shoemaker of the Lowell Observatory, who heads an informal Clementine 2 science advisory group that is scheduled to hold its first meeting this week, says that the Clementine 2 team will have more say in selecting science instruments than the first Clementine team did.

Other scientists are concerned that the Pentagon will begin working on strategies to deflect Earth-threatening asteroids before fully understanding the risk they pose. Ironically, it was Shoemaker who chaired a recent panel recommending that NASA fund a long-term observing programme to characterize that risk, but the space agency declined (see Nature 377, $185 ; 1995$ ).

Now, says Shoemaker, the Pentagon may pick up the ball. "NASA didn't bid to do it, and it might then fall by default to the Air Force," he says. Shoemaker and others say it falls naturally within the US Air Force's military mission, and has been seriously discussed in the Pentagon for some time. In fact, says Nozette, taking on the mission of defending against asteroids has generated "surprisingly little opposition in the Air Force hierarchy so far". Tony Reichhardt 